\title{
TEACHING Against ENTITLEMENTALITY
}

\author{
Joel Hilchey \\ McMaster University \\ hilchejm@mcmaster.ca
}

\begin{abstract}
It seems more and more students feel "entitled". "Entitlementality" in action looks like sitting around, lacking accountability, expecting success to come without effort or work, and surprised and offended when things don't work out perfectly. It looks like students who expect teachers to do a high level of their work and their thinking FOR them.

Meanwhile, borders are opening, careers are everchanging, and economies are shaky. An attitude of entitlement in this age is a recipe for failure. Educators MUST combat this "entitlementality."

Society, although well-intentioned, has unfortunately caused the problem. A relatively "good" and easy life, disconnectedness from nature and other real systems, and a mangled message of "empowerment" decoupled from hard work have symbolically changed L'Oreal's slogan from "I'm worth it" into a whiny "I deserve it."

This is a battle worth fighting, and the paper offers techniques to do it - good goals in and of themselves: creativity, empathy, gratitude, and meaningful personal projects.
\end{abstract}

Keywords: Entitlement, Teaching, Millennial Generation, Narcissism, Laziness,

\section{INTRODUCTION}

This paper presents ideas in preliminary form. It is meant as a discussion starter, and presents a "draft zero" of a theory of entitlementality - what it looks like, how it arises and what might be done about it.

It is hoped that further innovative experiments and critical studies will be undertaken to more deeply understand, and hopefully combat this growing mindset (if it is indeed something that turns out to be negative).

\section{ENTITLEMENTALITY - DRAFT ZERO}

\subsection{Entitlementality in Action}

In general, entitlementality in action looks like people expecting exceptional results while investing lazy efforts. Students are smart, capable and motivated to achieve, but there is a growing accompanying attitude that success should be guaranteed. There seem to be a number of common perceptions which embody this attitude.

2.1.1 A Degree $=$ A Job. Many students, particularly those in engineering, feel that the acquisition of a degree guarantees a job out of school. Furthermore, students' salary expectations are often higher than realistic.

2.1.2 Enrollment $=$ Degree. Less quantifiable, although still present, is the idea that obtaining the degree should not require any strict achievements. In courses where attendance is required, many students are noticeably upset at the lack of flexibility.

On the other hand, however, when asked if there should be an equivalency exam to earn an Engineering degree, a large majority of students say "no", indicating that most students still value the assignments and effort required to complete a degree.

2.1.3 An A+ is Guaranteed. Students seem remarkably quick to challenge low grades. While this is partially explained by game theory - students have no chance of grades increases unless they challenge their initial score many students offer flimsy reasons for the increases: "I really liked this class and want a higher grade;" "I am applying to grad school and need a higher grade;" or "I need an A in this course in order to keep a $\mathrm{C}$ overall and stay in my program." These arguments are not based on work performed, but on desired outcomes.

\subsection{How Does Entitlementality Arise?}

2.2.1 Life is Good. North Americans live in a relatively peaceful world where life is good and problems are small. It's a world of instant gratification, where stuff is cheap, and people are wealthy.

While Generation X grew up in an era concerned with nuclear war, today's youth are growing up in a relatively peaceful time. This is good. But our distance from struggle has left people with the impression that life should always be good, and the cost for this peace should be low, and borne by someone else. 
2.2.2 Disconnection from Natural Systems. The past few generations have seen a cultural shift in how humans interact with their environment. Specifically, there are fewer instances to be directly responsible for the things around us.

Author Matthew Crawford claims some high end cars, for example, no longer have an oil dipstick.[2] Instead, you're sent an email from some place when your oil gets low. Many people don't fix their own products anymore, and many products are not made to be fixed at all, and are instead thrown away and replaced when damaged. Because of this difficulty in connecting with the physical world, it seems many people are left bereft of an understanding and appreciation for the intricacies that make the items in our lives work.

Technical specialization is in part to blame for this, as it gives those with specific knowledge the mastery over a given domain, but it can simultaneously create the illusion that the domain can exist independent of other factors. The operations of an iphone are incomprehensible to all but those in a few distinct fields. However, even if a person IS curious, the electronics themselves are not physically accessible. If it breaks, therefore, the user cannot be responsible for it, and MUST blame someone else. In short, if you cannot affect the world physically, it is unlikely that you will feel responsible for it. This lack of responsibility is precisely what causes the missing senses of ownership and agency.

Furthermore, humans spend less time outside amongst plants, trees, and nature. In the natural environment, natural consequences abound. A tree snapped at the trunk will not re-grow in a day or a week. In the virtual world of video games, a building can be rebuilt with the press of a reset button.

2.2.3 An Overgrown Sense of Self-Importance. In a land of opportunity, where anyone can theoretically achieve anything, a mangled message of empowerment has been decoupled from hard work. L'Oreal's "I'm worth it" campaign might well have morphed in an entitled "I deserve it."

In part because there are good news stories of unlikely successes and instead wealth, people believe that they too should have such opportunities. People are notoriously bad at guessing probabilities, and it seems likely that people overestimate the probability that they will find immediate success. This is the same phenomenon at play when people buy lottery tickets. People, believing they will beat the odds, act unwisely.

Additionally, electronic data collection has enabled exceptionally customized experiences and targetted advertisements. This customized world likely contributes to the sense that the individual is paramount. The "mecentric" society is a society in which narcissism abounds, and since computers can cater to our wishes and a great deal of our experiences can be customized, it creates a great deal of internal tension during circumstances that must yield to the pressures of a group. Society, for better or worse, is a collective experience, and decisions cannot be exclusively and entirely based upon any given individual's needs.

\subsection{What Are Our Options As Educators?}

2.3.1 Life is Good. To combat the downsides arising from the fact that "life is good", educators can encourage risk-taking, experiential education, and create a safe space for vulnerability.

When people feel "ownership" over their actions, they are more likely to appreciate their progress and circumstance.

A special note on failure: When students (or adults) "fail", or more generally, when they make a mistake, they are presented with the opportunity to reflect and grow. Most education systems and business approaches treat mistakes as a thing to be avoided. There's so much pressure to NOT make mistakes that people often invest significant time, money, and energy into covering up mistakes in order to manage an image, rather than paying attention to improving results. While it's good that people are willing to work for something, it's an interesting quirk that the efforts ignore, rather than embrace, the imperfections in the process, choosing to believe that everything should appear seamless. This appearance then further reinforces that life should be easy.

2.3.2 Disconnection from Natural Systems. To reconnect students with the material world and natural systems, educators can encourage students to play outside, connect with nature, and do things with their hands for real. Gardening is a particularly strong connector, as it layers natural systems, consequences of vulnerability, and individual agency.

Consider removing students from the traditional classroom and using the time to explore, or have assignments that require real life doing. Even within the conventional classroom, educators can again push experiential education, and provide activities that offer the students excuses to adventure and experiment.

As a note, most traditional laboratories do indeed have elements that connect students to real life. The study of uncertainty is perhaps a more traditional way to connect students' theory to practice. When students are frustrated with resulted not being perfect, educators can take the opportunity to help the student appreciate the messy and imprecise nature of reality. This tension between theory and practice should be explored further as it relates to student frustration and expectation. 
2.3.3 An Overgrown Sense of Self-Importance. To battle narcissism and this pervasive yet illusory sense of self-aggrandizement, educators must find creative ways to broaden students' perspectives.

Time, for example, teaches us that nothing is permanent. Geography teaches us we are fortunate to live in North America. Critically examining success teaches us that achievement requires perseverance.

Educators can find opportunities to link a students' perspective to course material.

A word can be said for diversity at this point, as it is a worthy tool to teach humility. Simply exposing the breadth of perspectives available and examining the diversity within the room will create an opportunity for a student to recognize the limited scope which often dominates the classroom conversation.

\subsection{Alternatives to Entitlementality}

Some feelings and mentalities do no co-exist easily. When one is hungry, for example, it is difficult to imagine the feeling of being full. Similarly, when one is angry, it is difficult to envision feeling joy. As entitlementality is a mindset, it is likely to have similar qualities, whereby the presence of other attitudes and feelings prohibit entitlement to take hold. Some of these alternatives are explained briefly here.

2.4.1 Gratitude. When we feel grateful we appreciate what is, instead of expecting more and more. We also increase our happiness and, in turn, increase our willingness to work hard and take on challenges.

2.4.2 Contribution. When contribution is emphasized, people focus on what they give rather than on what they get. Asking questions that emphasize the work people did: "What are you contributing right now?"; "What did you do to earn this?"; "What effort have you put in?"
2.4.3 Ownership. When we feel accountable for an outcome, we learn from failures instead of spreading blame externally. This sense of ownership can be embedded in assignments, learning styles, and extracurricular experiences.

\section{CONCLUSIONS}

Battling entitlementality in education has a number of "bonus" outcomes including increasing the focus on basic life skills, relationships, personal and societal health, appreciation of the land and nature, patient problem solving, and a healthier approach to mistakes and failure.

An additional benefit is that once students find themselves within these new projects and modes of thinking, and stepping outside of their entitlementality, they almost immediately see the benefit. Although they wouldn't have chosen it to begin with, they now wouldn't choose to go back.

Teaching to combat entitlementality might just be an option to unify a whole generation of teachers in a combined mission to make the world better, one student at a time. It's what most teachers say teaching is all about!

\section{Acknowledgements}

A special thank you goes to the 2012 Fall Engineering \& Social Responsibility Class at McMaster University for sharing their ideas and experiences with entitlementality.

\section{References}

[1] Matthew B Crawford, Shop Class as Soul Craft: An Inquiry into the Value of Work. New York, New York: Penguin Press: 2009.

[2]Dr. Alex Russell with Tim Falconer, Drop the Worry Ball: How to Parent in the Age of Entitlement. Mississauga, Canada: John Wiley \& Sons Canada, Ltd: 2012 ISBN: 978$1=11812-494-9\}$ 